\title{
Sinus of valsalva aneurysm repair in an octogenarian using CorMatrix ECM ${ }^{\circledR}$
}

\author{
Juan A. Siordia,, Christopher Piercecchi, Todd R. Golden, Samata R. Paidy, Sreekumar Subramanian \\ Department of Surgery, University of Arizona Medical Center, University of Arizona, Tucson, AZ, United States
}

Received: July 17, 2015

DOI: $10.5430 /$ css.v2n2p6
Accepted: February 17, $2016 \quad$ Online Published: February 19, 2016

URL: http://dx.doi.org/10.5430/css.v2n2p6

\begin{abstract}
Introduction: Unruptured sinus of Valsalva aneurysms are surgically treated after change in clinical presentation or increased size on serial echocardiography. Prostheses such as Dacron grafts and Gortex are notably used, but use of CorMatrix has not previously been reported. The following case presents the first reported use of CorMatrix for sinus of Valsalva repair.

Presentation of case: An 84-year-old male presented with a $6.3 \mathrm{~cm}$ right sinus of Valsalva aneurysm seen with echocardiography. Surgical sinus of Valsalva repair involved inserting BioGlue within the aneurysm and closing the defect with CorMatrix. Twomonth follow-up showed no significant postoperative complications.

Discussion: The presented case reports the first use of CorMatrix for sinus of Valsalva repair and represents the oldest patient in the world to undergo this surgery. Sinus of Valsalva aneurysms are asymptomatic in $25 \%$ of cases and are incidentally found with echocardiography. Although survival in elderly patients specifically is unknown, postoperative survival overall is $88 \%$ at 20 years. CorMatrix is commonly used for structural heart defect repairs, but has not been described for sinus of Valsalva repairs.

Conclusions: CorMatrix presents as a suitable prosthesis for sinus of Valsalva aneurysm repair.
\end{abstract}

Key Words: Sinus of valsalva aneurysm, Surgical repair, Cardiac surgery, CorMatrix

\section{INTRODUCTION}

A sinus of Valsalva aneurysm is a rare, most often congenital condition defined as a dilatation of at least one of the sinuses formed by the aortic leaflets within the aortic root-most commonly from the right sinus of Valsalva (with the noncoronary and left coronary sinus less often respectively). ${ }^{[1]}$ The upper limit of normal for sinus diameter in men is $4.0 \mathrm{~cm}$ and $3.6 \mathrm{~cm}$ in women. ${ }^{[2]}$ Sinus of Valsalva aneurysm is often associated with other congenital conditions, most commonly ventricular septal defect, in 30\%-60\% of patients, while aortic insufficiency and bicuspid aortic valve are each observed in less than a third and less than a tenth of patients. ${ }^{[3-5]}$ Although most commonly congenital, sinus of Valsalva aneurysm may also be acquired following decelera- tion trauma, or due to infectious (e.g. bacterial endocarditis, syphilitic aortitis, and tuberculosis) or degenerative disease. The incidence of sinus of Valsalva aneurysm is $<0.1 \%$ of the general population and they comprise $0.1 \%$ to $3.5 \%$ of all congenital cardiac defects. ${ }^{[4,6]}$ Additionally they are much more common in males (4:1) and in Eastern and Asian countries compared to Western countries (5:1). ${ }^{[4,7-10]}$ Unruptured sinus of Valsalva aneurysms are most often asymptomatic and are usually found by routine 2-dimensional echocardiography. ${ }^{[11]}$ Most reported cases arise from a rupture of the aneurysm, producing symptoms including dyspnea, edema, and orthopnea. ${ }^{[12]}$ The mean survival for patients with untreated ruptured sinus of Valsalva aneurysm is 1-2 years. ${ }^{[7,13]}$ Early surgical intervention via patch closure is the preferred

*Correspondence: Juan A. Siordia; Email: jas@email.arizona.edu; Address: 329 N. Norris Ave., Tucson, Arizona, 85719, United States. 
treatment for congenital cases.

Elderly patients that present with sinus of Valsalva aneurysms are frequently rejected for aggressive surgical treatment due to safety risks and ethical issues. Most are discharged to hospice care or an intensive care environment after managing heart failure symptoms. ${ }^{[12]}$ Aggressive intervention, if performed correctly, can still provide the favorable solution. ${ }^{[14]}$

This case also involved the use of extracellular matrix developed by CorMatrix ${ }^{\circledR}$ (CorMatrix Cardiovascular Inc., Alpharetta, Georgia) for patch closure. The matrix is bioengineered as an acellular porcine extracellular matrix harvested from the small intestine submucosa. ${ }^{[15]}$ The product was used to shunt the aneurysmal defect containing thrombi.

\section{CASe PResentation}

An 84-year-old male presented with an asymptomatic right sinus of Valsalva aneurysm measuring $6.3 \mathrm{~cm}$ in diameter. This was discovered on echocardiographic evaluation of a cardiac murmur and associated with a normal EKG. Past medical history was significant for aortic insufficiency along with coronary artery disease involving the posterior descending artery. Transesophageal echocardiography (see Figure 1) and cardiac catheterization revealed a large right sinus of Valsalva aneurysm. These findings justified cardiac surgical intervention.

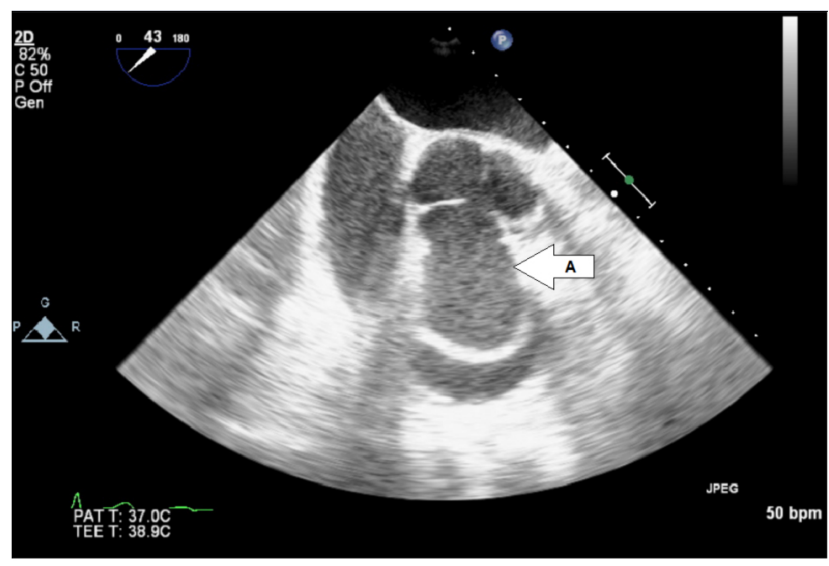

Figure 1. Transesophageal echocardiography presenting a $>4.5 \mathrm{~cm}$ right sinus of valsalva aneurysm (A). Moderate aortic regurgitation was also noted during this study.

Via a median sternotomy, the May 2012 procedure included exclusion of this aneurysm using a sheet of CorMatrix ECM $^{\circledR}$, suspension of the commissure between the right and non-coronary sinuses, and saphenous vein graft bypass to the right coronary artery. The CorMatrix was secured from the interface of the sinus superiorly to the top of the aneurysm, excluding the sinus of Valsalva aneurysm from Published by Sciedu Press circulation - this effectively encased the aneurysmal section of clotted blood. BioGlue ${ }^{\mathrm{R}}$ (CryoLife, Kennesaw, Georgia) was added within the aneurysm sac to facilitate thrombosis, eliminating external bowing of the repaired section. Postoperative transesophageal echocardiography revealed complete thrombosis of the aneurysm sac (see Figure 2) and postoperative day 5 echocardiography demonstrated normal left ventricular size (EF 60\%-69\%) with the sinus of Valsalva mildly dilated, at $3.8 \mathrm{~cm}-4.4 \mathrm{~cm}$.

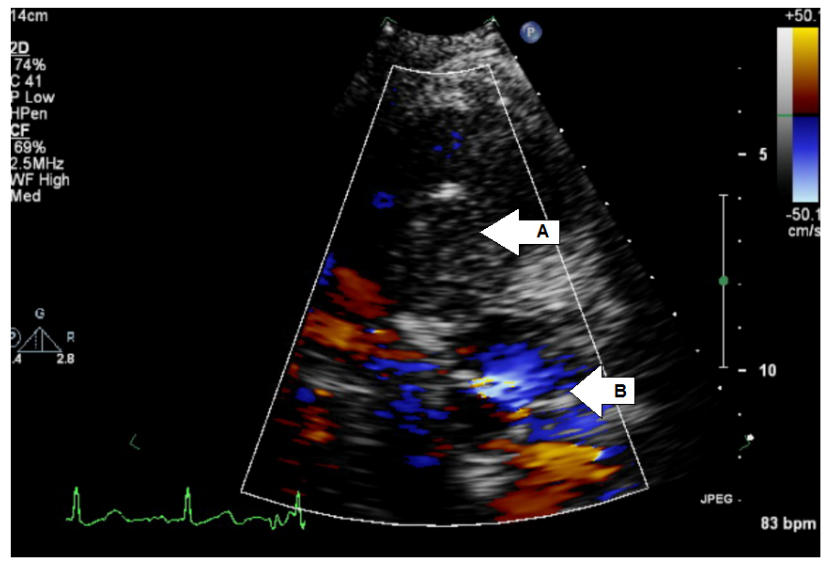

Figure 2. Post-operative echocardiogram status-post sinus of valsalva aneurysm repair with CorMatrix. Dilated right sinus of valsalva aneurysm at $\sim 4 \mathrm{~cm}$ filled with thrombi and BioGlue (A). Sinus of valsalva aneurysm buldging into the right ventricular outflow tract. Moderate valvular aortic regurgitation also measured (B).

Following an uncomplicated hospital course, the patient was discharged on postoperative day 5. Apart from continuing his previous daily medication regimen (Lorsartan $100 \mathrm{mg}$, Finasteride $1.25 \mathrm{mg}$, Aspirin $81 \mathrm{mg}$ ), upon discharge his Losartan was cut in half to $50 \mathrm{mg}$ daily and both metoprolol $12.5 \mathrm{mg}$ b.i.d. and docusate $100 \mathrm{mg}$ b.i.d. were added. The patient remained asymptomatic at 1-month and 2-month follow-up and was followed by his community physician.

\section{DisCUSSION}

Sinus of Valsalva aneurysm arise from incomplete fusion of the aortic media elastin layer and the aortic annulus fibrosa. Initial pathophysiology involves local turbulence and eventual formation of an aneurysmal sac. ${ }^{[16]}$ Twenty-five percent of sinus of Valsalva aneurysms are clinically asymptomatic and detected incidentally via echocardiography. Unruptured aneurysms rarely may cause symptoms via obstruction of the right ventricular outflow tract. ${ }^{[11]}$ Rupture typically leads to large left-to-right shunts and severe congestive heart failure which are commonly treated surgically, although a percutaneous approach is becoming more widely adopted only if 
symptoms are not primarily caused by coinciding pathologies including aortic insufficiency and ventricular septal defects. ${ }^{[16,17]}$ Small asymptomatic stable aneurysms are treated with anticoagulation and close follow-up including MRI or echocardiography monitoring. ${ }^{[9,10,18,19]}$ Successful surgical repair was first reported in 1957 and is recommended when the sinus grows to $>50 \%$ larger than the average size of the other two sinuses, compresses surrounding chambers or origin of the main coronary arteries, increases in consecutive echocardiograms ( $>0.5 \mathrm{~cm} /$ year) or presents incidentally during cardiac surgery. ${ }^{[20-25]}$ In order to avoid complications associated with aneurysm enlargement or endocarditis, early surgical repair has been recommended especially since this surgery is associated with low morbidity and mortality, however this has not been established in elderly patients. ${ }^{[9,24,26]}$

A study involving a 33-year single center experience found patients undergoing sinus of Valsalva aneurysm repairs were more commonly males $(70 \%)$ and the average age was 30 years. ${ }^{[27]}$ Hospital course morbidity and mortality was $2 \%$. ${ }^{[1,27]}$ Survival was $94 \%$ at 10 years and $88 \%$ at 20 years. ${ }^{[27]}$ However, studies concerning repair in octogenarians are very limited and inconclusive. There is one report of an octogenarian in Japan undergoing surgical repair following ruptured right sinus of Valsalva aneurysm. With a patch closure of the defect, the patient presented with no further complications after intervention. ${ }^{[14]}$

CorMatrix ECM is frequently used in reconstruction of the pericardium, repair of vascular stenosis, and closure of intracardiac defects. Long-term studies concerning its reliability and durability are limited as CorMatrix first received FDA approval in 2005 and became commercially available in 2006. A 2014 seven case series with short term results supported CorMatrix for aortic root enlargement. ${ }^{[28]}$ An- other study compared the outcomes of CorMatrix with that of autologous pericardium. CorMatrix was associated with intense inflammation that did not resolve even after 9 months. Histology showed a high number of eosinophils and giant cells. Remodeling and reabsorption of the material along with reconstruction of native tissue was minimal. Contrasting results were seen with autologous pericardial tissue, which showed minimal inflammation, significant remodeling, and promotion of native tissue growth. The only negative finding found with autologous pericardial tissue use was extensive calcification, which was not seen with CorMatrix. Nevertheless, CorMatrix shows significant inferiority compared to autologous pericardial tissue in terms of repair of congenital cardiac defects. This may be explained by autologous pericardial tissue being an allograft and CorMatrix, being from the mucosa of pig small intestine, a xenograft. This theory is supported by animal studies showing superior results with CorMatrix in cardiac repairs in pig models. ${ }^{[29]}$

Prostheses such as Dacron ${ }^{\circledR}$ (Terumo, Somerset, New Jersey) or GORE-TEX ${ }^{\circledR}$ (W. L. Gore and Associates, Newark, Delaware) are effective repair mediums for sinus of Valsalva aneurysms, but the advantage of CorMatrix is its ability to transition histologically into aortic tissue. ${ }^{[30]}$ Outcomes comparing the prostheses in terms of sinus of Valsalva repair have not been performed; this case is the first use of CorMatrix for sinus of Valsalva repair. No complications have occurred after 2-month follow-up in the presented case, suggesting the value of the extracellular matrix as a potential suitable candidate for congenital sinus of Valsalva aneurysm repair. Further studies are required to definitively compare the prostheses for sinus of Valsalva aneurysm repair.

\section{CONFlicts OF INTEREST Disclosure}

The authors declare that they have no conflict of interest.

\section{REFERENCES}

[1] Weinreich M, Yu P, Trost B. Sinus of valsalva aneurysms: review of the literature and an update on management. Clin Cardiol. 2015; 38: 185-9. PMid: 25757442. http://dx.doi.org/10.1002/clc .22359

[2] Troupis JM, Nasis A, Pasricha S, et al. Sinus valsalva aneurysm on cardiac CT angiography: assessment and detection. J Med Imaging Radiat Oncol. 2013; 57: 444-7. PMid: 23870340. http: //dx.doi.org/10.1111/j.1754-9485.2012.02467.x

[3] Nakagiri K, Kadowaki T, Mormoto N, et al. Aortic root reimplantation for isolated sinus of valsalva aneurysm in the patient with marfan's syndrome. Ann Thorac Surg. 2012; 93: 49-51. PMid: 22365014 http://dx.doi.org/10.1016/j.athoracsur.2011.10.081

[4] Feldman DN, Roman MJ. Aneurysms of the sinus of Valsalva. Cardiology. 2006; 106: 73-81. PMid: 16612073. http://dx.doi.org

\section{$/ 10.1159 / 000092635$}

[5] Sakakibara S, Konno S. Congenital aneurysm of the sinus of Valsalva associated with ventricular septal defect. Am Heart J. 1968; 75: 595603. http://dx.doi.org/10.1016/0002-8703 (68) 90320-7

[6] Alkhafaji S, Carr CS, Alkhulaifi AAM, et al. Aneurysm of the sinuses of valsalva: Report of two cases and review of the literature. Heart Views. 2008; 9: 18-23.

[7] Moustafa S, Mookadam F, Cooper L, et al. Sinus of Valsalva aneurysms - 47 years of a single center experience and systematic overview of published reports. Am J Cardiol. 2007; 99: 1159-64. PMid: 17437748. http://dx.doi.org/10.1016/j.amjcard.2 006.11 .047

[8] Smith RL, Irimpen A, Helmcke FR, et al. Ruptured congenital sinus of Valsalva aneurysm. Echocardiography. 2005; 22: 625-8. 
PMid: 16060903. http://dx.doi.org/10.1111/j.1540-8175. 2005.40129.x

[9] Takach TJ, Reul GJ, Duncan JM, et al. Sinus of Valsalva aneurysm or fistula: management and outcome. Ann Thorac Surg. 1999; 68: 15737. http://dx.doi .org/10.1016/S0003-4975 (99)01045-0

[10] Goldberg N, Krasnow N. Sinus of Valsalva aneurysms. Clin Cardiol. 1990; 13: 831-6. PMid: 2282725. http://dx.doi.org/10.1002 /clc. 4960131204

[11] Gupta A, Gupta P, Prasanna K, et al. Continuous machinery murmur in an octogenarian. Age Ageing. 2004; 33(2): 201-3. PMid: 14960441. http://dx.doi.org/10.1093/ageing/afh066

[12] Pastor A, Rey M, Farre J. Sinus of valsalva aneurysm. Rev Esp Cardiol. 2011; 64: 150. PMid: 21190776. http://dx.doi.org/10. 1016/j.recesp. 2009.12.001

[13] Ring WS. Congenital Heart Surgery Nomenclature and Database Project: aortic aneurysm, sinus of Valsalva aneurysm, and aortic dissection. Ann Thorac Surg. 2000; 69: 147-63. http://dx.doi.o $\mathrm{rg} / 10.1016 / \mathrm{S} 0003-4975$ (99)01242-4

[14] Hashimoto T, Niu S, Adachi S, et al. A case report of surgical repair of ruptured aneurysm of sinus valsalva in aged (84 years old). Kyobu Geka. 1999; 52: 780-2. PMid: 10453168.

[15] Quarti A, Nardone S, Colaneri M, et al. Preliminary experience in the use of an extracellular matrix to repair congenital heart diseases. Interact Cardiovasc Thorac Surg. 2012; 13: 569-72. PMid: 21979987. http://dx.doi.org/10.1510/icvts.2011.280016

[16] Edwards JE, Burchell HB. The pathological anatomy of deficiencies between aortic root and the heart including aortic sinus aneurysms. Thorax. 1957; 12: 125-39. http://dx.doi.org/10.1136/thx.1 2.2.125

[17] Kuriakose EM, Bhatla P, McElhinney DB. Comparison of reported outcomes with percutaneous versus surgical closure of ruptured sinus of valsalva aneurysm. Am J of Cardiol. 2015; 115: 392-8. PMid: 25488356. http://dx.doi.org/10.1016/j.amjcard.2 014.11 .013

[18] Afshar AH, Kolesnikov S, Pourafkari L, et al. Right valsalva sinus aneurysm protruding into the right ventricle: a case report. J Cardiovasc Thorac Res. 2015; 7: 126. PMid: 26430502. http: //dx.doi.org/10.15171/jcvtr.2015.27

[19] Munk MD, Gatzoulis MA, King DE, et al. Cardiac tamponade and death from intrapericardial rupture [corrected] of sinus of Valsalva aneurysm. Eur J Cardiothorac Surg. 1999; 15: 100-2. http: //dx.doi.org/10.1016/S1010-7940(98)00269-3

[20] Lillehei CW, Stanley P, Varco RL. Surgical treatment of ruptured aneurysms of the sinus of Valsalva. Ann Surg. 1957; 146: 45972. PMid: 13459295. http://dx.doi.org/10.1097/0000065 8-195709000-00014
[21] Bricker AO, Avutu B, Mohammed TL, et al. Valsalva sinus aneurysms: findings at $\mathrm{CT}$ and MR Imaging. Radiographics. 2010; 30: 99-110. PMid: 20083588. http://dx.doi .org/10.1148/rg. 301095719

[22] Martínez-Comendador J, Gualis J, Martín CE, et al. Left main coronary artery compression by a left sinus of valsalva aneurysm. Interact Cardiovasc Thorac Surg. 2013; 16: 713-4. PMid: 23355647. http://dx.doi.org/10.1093/icvts/ivt003

[23] Hiratzka LF, Bakris GL, Beckman JA, et al. 2010 ACCF/AHA/AATS/ACR/ASA/SCA/SCAI/SIR/STS/SVM guidelines for the diagnosis and management of patients with thoracic aortic disease: executive summary. A report of the American College of Cardiology Foundation/American Heart Association Task Force on Practice Guidelines, American Association for Thoracic Surgery, American College of Radiology, American Stroke Association, Society of Cardiovascular Anesthesiologists, Society for Cardiovascular Angiography and Interventions, Society of Interventional Radiology, Society of Thoracic Surgeons, and Society for Vascular Medicine. Catheter Cardiovasc Interv. 2010; 76: 43-86. http://dx.doi.org/10.1002/ccd.22537

[24] Reddy SM, Bisoi AK, Sharma P, et al. Surgical repair of multiple unruptured aneurysms of sinus of Valsalva. Interact Cardiovasc Thorac Surg. 2009; 9: 709-11. PMid: 19592417. http://dx.doi .org/10. 1510/icvts. 2009. 205989

[25] Vural KM, Sener E, Tasdemir O, et al. Approach to sinus of valsalva aneurysm: a review of 53 cases. Eur J Cardiothorac Surg. 2001; 20: 71-6. http://dx.doi.org/10.1016/S1010-7940(01) 007 58-8

[26] Naka Y, Kadoba K, Ohtake S, et al. The long-term outcome of a surgical repair of sinus of Valsalva aneurysm. Ann Thorac Surg. 2000; 70: 727-9. http://dx.doi.org/10.1016/S0003-4975(00) 01499 $-5$

[27] Yan F, Abudureheman M, Huo Q, et al. Surgery for sinus of valsalva aneurysm: 33-year of a single center experience. Chin Med J. 2014; 127(23): 4066-70.

[28] Brinster DR, Patel JA. The use of CorMatrix extracellular matrix for aortic root enlargement. J Cardiothorac Surg. 2014; 19: 178. PMid: 25407632. http://dx.doi.org/10.1186/s13019-014 -0178-5

[29] Zaidi AH, Nathan M, Emani S, et al. Preliminary experience with porcine intestinal submucosa (CorMatrix) for valve reconstruction in congenital heart disease: histologic evaluation of explanted valves. J Thorac Cardiovasc Surg. 2014; 148: 2216-25. PMid: 24698560. http://dx.doi.org/10.1016/j.jtcvs.2014.02.081

[30] Uchikawa S, Ito Y, Hayashi K, et al. Surgical repair of extracardiac unruptured aneurysm of the sinus of valsalva; report of a case. Kyobu geka. 2003; 56: 879-82. PMid: 13677926. 